\title{
Publisher Correction: Mapping microscale wetting variations on biological and synthetic water- repellent surfaces
}

\author{
Ville Liimatainen (10) 1, Maja Vuckovac ${ }^{2}$, Ville Jokinen ${ }^{3}$, Veikko Sariola1,4, Matti J. Hokkanen,2, \\ Quan Zhou' \& Robin H.A. Ras (1D) 2,5
}

Correction to: Nature Communications https:/doi.org/10.1038/s41467-017-01510-7, published online 27 November 2017

The original version of this Article contained an error in Fig. 2b. The $y$-axis label in Fig. 2b was incorrectly labelled 'Snap-in force $(\mu \mathrm{N})$ '. In the correct version, the axis is labelled 'Snap-in force $(\mathrm{nN})$ '.

In the original version of this Article, the "Butterfly wings" section of the Methods incorrectly stated the name of the butterfly as 'Golden bird'. In the correct version, the name of the butterfly is 'Golden birdwing'.

These have now been corrected in both the PDF and HTML versions of the article.

Published online: 09 February 2018

\begin{abstract}
(c) (i) Open Access This article is licensed under a Creative Commons Attribution 4.0 International License, which permits use, sharing, adaptation, distribution and reproduction in any medium or format, as long as you give appropriate credit to the original author(s) and the source, provide a link to the Creative Commons license, and indicate if changes were made. The images or other third party material in this article are included in the article's Creative Commons license, unless indicated otherwise in a credit line to the material. If material is not included in the article's Creative Commons license and your intended use is not permitted by statutory regulation or exceeds the permitted use, you will need to obtain permission directly from the copyright holder. To view a copy of this license, visit http://creativecommons.org/licenses/by/4.0/.
\end{abstract}

(C) The Author(s) 2018

\footnotetext{
${ }^{1}$ Department of Electrical Engineering and Automation, Aalto University School of Electrical Engineering, Maarintie 8, 02150 Espoo, Finland. ${ }^{2}$ Department of Applied Physics, Aalto University School of Science, Puumiehenkuja 2, 02150 Espoo, Finland. ${ }^{3}$ Department of Chemistry and Materials Science, Aalto University School of Chemical Technology, Tietotie 3, 02150 Espoo, Finland. ${ }^{4}$ Faculty of Biomedical Sciences and Engineering, Tampere University of Technology, Korkeakoulunkatu 3, 33720 Tampere, Finland. ${ }^{5}$ Department of Bioproducts and Biosystems, Aalto University School of Chemical Engineering, Kemistintie 1, 02150 Espoo, Finland. Ville Liimatainen and Maja Vuckovac contributed equally to this work. Correspondence and requests for materials should be addressed to Q.Z. (email: quan.zhou@aalto.fi) or to R.H.A.R. (email: robin.ras@aalto.fi)
} 